\title{
Florecimiento humano: ¿una agenda utopista?
}

\author{
Ruth Levitas
}

El presente artículo señala que, dentro del discurso político contemporáneo, la 'felicidad' y el 'bienestar' tienen una relación ambigua con la pobreza. Se afirma que el dinero no puede comprar la felicidad, sin embargo, las investigaciones sobre la pobreza y la exclusión social demuestran que se trata de factores perjudiciales para el florecimiento humano y el bienestar.Tras tocar dichos temas, el artículo aborda cuestiones acerca de la necesidad, la habilidad y la capacidad humanas; analiza la conceptuación de Julio Boltvinik sobre la riqueza, la pobreza y el florecimiento humano. Concluye argumentando en favor de un pensamiento más explícitamente utópico que permita un diálogo reflexivo en torno a las capabilities valoradas y las condiciones de su desarrollo.

PALABRAS CLAVE: felicidad, bienestar, utopía, pobreza, indicadores sociales

This paper argues that 'happiness' and 'well-being' in contemporary political discourse stand in ambiguous relation to poverty. It is claimed that money cannot buy happiness, yet research on poverty and social exclusion demonstrates that these are detrimental to human flourishing and well-being. It moves from these discussions to questions of human need, capability and capacity; looks at the conceptualization of human wealth, poverty and flourishing in the work of Julio Boltvinik. It concludes with a plea for more explicitly utopian thinking to enable a reflexive dialogue about valued capabilities and the conditions of their development.

KEY WORDS: happiness, well-being, utopia, poverty, social indicators

\footnotetext{
RUTH LEVITAS: Universidad de Bristol, Bristol, Reino Unido ruth.levitas@bristol.ac.uk

Traducción del inglés: Ángel Javier Dorantes y Sotomayor Revisión: Julio Boltvinik
}

Desacatos, núm. 23, enero-abril 2007, pp. 87-100.

Recepción: 12 de agosto de 2006 / Aceptación: 9 de octubre de 2006 
$\mathrm{H}$ a habido una proliferación bibliográfica sobre el florecimiento humano, la felicidad, el bienestar y la calidad de vida, que va desde la discusión conceptual, histórica y filosófica hasta intentos de definición operativa y medición. Son ambiguas las relaciones entre esas publicaciones y los temas de pobreza y exclusión social. Las primeras pueden servir para ilustrar el profundo empobrecimiento humano que resulta de las carencias materiales. También pueden demostrar el riesgo de confiar en mediciones convencionales del crecimiento económico aun en la evaluación del bienestar económico, ni se diga del humano. O incluso pueden alinearse con el discurso de que "el dinero no compra la felicidad", y caer en el riego de soslayar la importancia fundamental de las cuestiones distributivas. Este riesgo es mayor cuando los temas del florecimiento humano son planteados en contextos abrumadoramente neoliberales.

Este artículo argumenta que el florecimiento humano es intrínsecamente un concepto utópico en tanto que se enfoca, más allá del presente, a un orden social transformado como condición necesaria de dicho florecimienentonces, en sí mismo, el problema de la utopía. Como Marx y los marxistas siempre lo entendieron, es imposible imaginarlo, porque no podemos prever ni cerrar anticipadamente (foreclose) las necesidades, deseos y capacidades de los seres humanos del futuro; no sabemos lo que ellos o nosotros podamos ser entonces. Aun así, estamos obligados a intentarlo, pues es solamente el imaginarnos el mundo y a nosotros mismos de otra manera lo que nos proporciona un punto de apoyo para el cambio por la vía de la crítica de las condiciones actuales. Marxistas como Herbert Marcuse (1955, 1968, 1970a, 1970b) y Frederic Jameson $(1981,1984,2004)$ han insistido en la importancia de la búsqueda utópica, si bien a menudo reconociendo su necesario fracaso. El intento de conceptualizar la utopía o el florecimiento humano en el presente siempre y necesariamente conduce a estrechar y distorsionar estos conceptos, incluso cuando apuntan a algo que está más allá de ellos mismos. Resulta por ello esencial la separación de los registros de la existencia utópica y de la real, a fin de que los límites actuales de las ideas sobre el bienestar, y la necesidad de un cambio estruc-

tural radical como la condición del bienestar, sean enfocados más claramente. Este ensayo comienza con una mirada a las discusiones contemporáneas sobre medición de felicidad y bienestar en el dominio de la política. Va desde las cuestiones de necesidad humana, capability ${ }^{1} \mathrm{y}$ capacidad, hasta explorar la conceptualización de la riqueza y la pobreza humanas en términos del florecimiento humano en el trabajo de Julio Boltvinik (2005). Concluye con un exhorto por un pensamiento más explícitamente utópico para favorecer un diálogo reflexivo acerca de las capabilities valoradas y las condiciones de su desarrollo.

\section{¿PUEDE EL DINERO COMPRAR LA FELICIDAD?}

Las palabras de Ogden Nash fueron incorporadas por S. J. Perelman en el libreto para la obra musical de Kurt Weill, Un toque de Venus:

Una forma de ser muy feliz es ser muy, muy, muy rico.

Hay formas del placer humano

que no se compran con tesoros, pero no recuerdo exactamente cuáles.

He escuchado a mis amigos adinerados quejarse: hay problemas que el dinero no puede remediar; pero un problema es un problema es un problema $\mathrm{y}$ es dos veces problema si la persona es pobre ${ }^{2}$.

${ }^{1}$ Tal como se señala en Boltvinik (2005), cualquier traducción de 'capability', tal como la usa Sen, tiende a darle una precisión que no tiene en su obra y que, por tanto, resultaría falsa. En el uso de Sen capabilities no se refiere a capacidades humanas en el sentido usual del término, sino más bien a oportunidades económicas derivadas de los recursos que se poseen. La opción menos mala, entonces, es la de dejar el término en inglés. Aunque la autora no se refiere en esta frase a Sen, es casi inevitable en las ciencias sociales y la filosofía actuales que el término se asocie con él. [Nota de Julio Boltvinik, coordinador del número.]

2 One way to be very happy

Is to be very, very, very rich.

There are forms of human pleasure

That are not to be purchased with tresure,

But I can't remember exactly which

I've heard my wealthy friends complain

There are troubles that money can't cure;

But a trouble is a trouble is a trouble

And it's twice the trouble if a person is poor. 


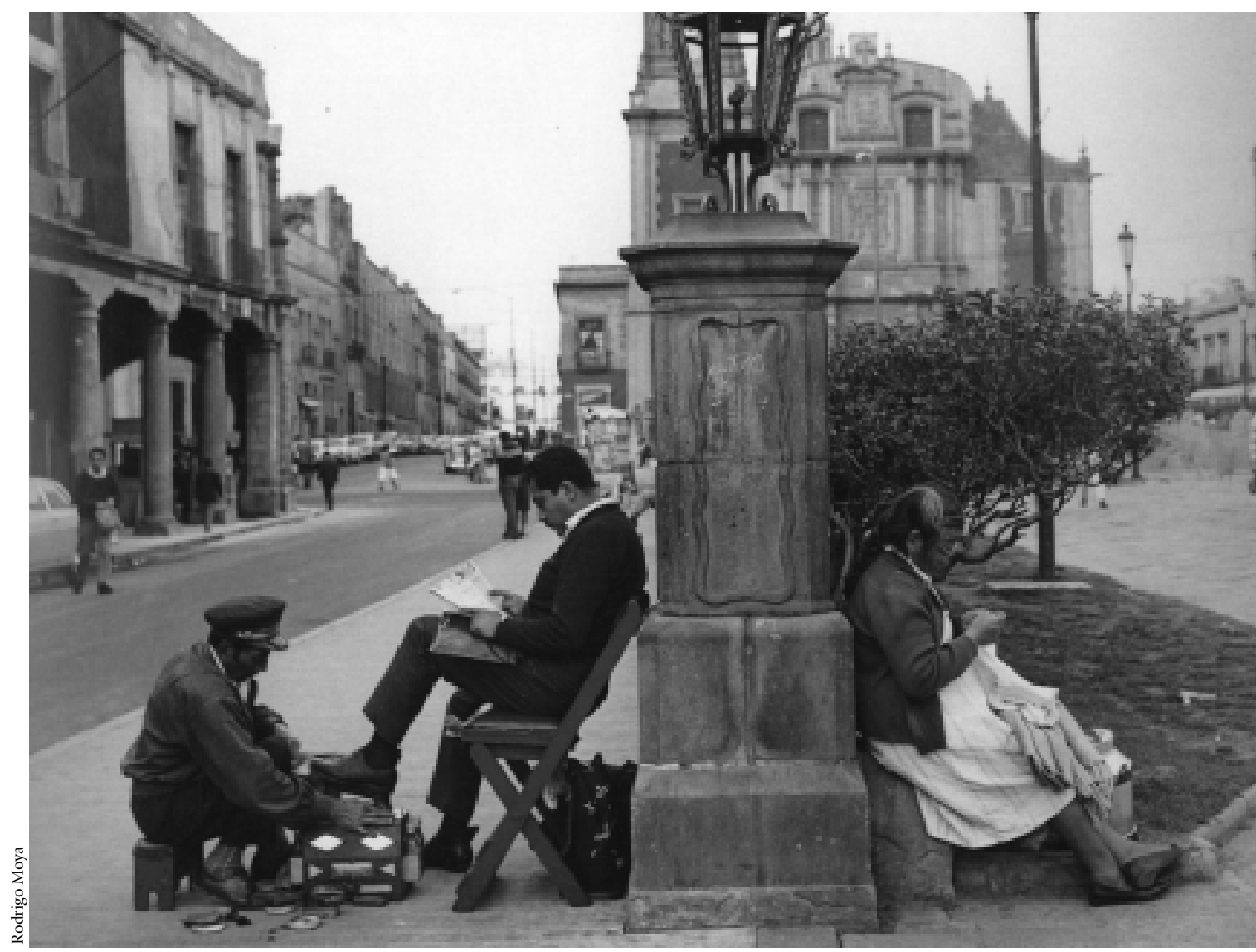

Avenida Virreyes, ciudad de México, 1963.

Los medios de comunicación del Reino Unido han estado promoviendo un mensaje diferente. Según Richard Layard, en su libro Happiness (2005), la British Broadcasting Corporation (BBC) igualmente declara que: "la felicidad del Reino Unido está disminuyendo". "El Reino Unido es menos feliz que en los años cincuenta, a pesar del hecho de que somos tres veces más ricos". Además nos dice: "una vez que el ingreso promedio alcanza alrededor de 10000 libras esterlinas al año, el dinero adicional no hace más feliz a un país". Una encuesta realizada bajo encargo especial "proporciona la primera evidencia de que la felicidad en el Reino Unido está decayendo - una tendencia ya verificada documentalmente en Estados Unidos". La evidencia de esto es que la proporción de personas que han dicho ser muy felices ha decaído de 52\% en 1957 a 36\% en 2006. No hay mención alguna al hecho de que la gente puede, en realidad, ser más feliz, pero sí a que puede tener expectativas de felicidad más elevadas o que admitir la infelicidad puede ser ahora más aceptable socialmente que hace cincuenta años. Este comentario también sostiene, puesto que los niveles de felicidad no han aumentado, que la "riqueza adicional no ha traído bienestar adicional" - lo que implica que las expresiones subjetivas de felicidad pueden ser adoptadas como medidas de bienestar ${ }^{3}$. Esta misma encuesta mostró que $81 \%$ de los encuestados está de acuerdo, y sólo 13\% dis-

${ }^{3}$ En $<$ http://newsvote.bbc.co.uk/1/hi/programmes/happiness_formula/ 4771908.stm>, consultado el 3-VII-2006. 
crepa de la afirmación de que: "El principal objetivo del gobierno debiera ser alcanzar el mayor nivel de felicidad del pueblo, no la mayor riqueza”. La mayoría, $52 \%$, coincidió en que: "Las escuelas debieran poner mayor énfasis en enseñar a los estudiantes cómo alcanzar una vida personal feliz y menor énfasis en educarlos para el mundo del trabajo"4.

Más todavía, la BBC estimula a los televidentes a revisar su felicidad en línea. Esta prueba, diseñada por el profesor Ed Diener de la Universidad de Illinois, Estados Unidos, establece las siguientes cinco proposiciones con las que se puede estar de acuerdo o discrepar, en una escala de siete puntos:

- En la mayoría de sus formas, mi vida es ideal.

- Las condiciones de mi vida son excelentes.

- Estoy satisfecho con mi vida.

- Hasta ahora he obtenido las cosas importantes que deseo en la vida.

- Si pudiera vivir mi vida de nuevo, no cambiaría casi nada.

Estas proposiciones pueden ser cuestionadas en el sentido que confunden la felicidad con la autocomplacencia. En cualquier caso, yo califiqué ligeramente por debajo del promedio en cuanto a satisfacción en la vida. El envío de este resultado iba acompañado con una homilía que rezaba: "Las personas que califican en este rango tienen pequeños pero significativos problemas en diversas áreas de sus vidas, o tienen muchas áreas en las que se desempeñan bien, pero una de ellas manifiesta un problema sustancial para ellas [...] Si continuamente estás más o menos insatisfecho en muchas áreas de tu vida, algunos cambios podrían ser convenientes". Concluye diciendo: "Con tiempo y trabajo persistente, la satisfacción de las personas normalmente aumenta [...] Cuando una persona está crónicamente insatisfecha, debiera mirarse y preguntar si requiere o no desarrollar actitudes más positivas ante la vida y el mundo" 5 .

\footnotetext{
${ }^{4}$ Ibid.

5 En <http://newsvote.bbc.co.uk/1/hi/ptogrammes/happiness_ formula/4785402.stm $>$, consultado el 3-VII-2006.
}

La preocupación por la felicidad y su medición no se reduce evidentemente a Gran Bretaña, la que aparentemente se ubica en octavo lugar en los rangos internacionales. Una búsqueda sobre felicidad en línea en Google arroja 111 millones de resultados. Los primeros diez se refieren a sitios de autoayuda de "cómo ser feliz". El Reino Unido está representado por 'El Proyecto Felicidad', y los Países Bajos por la Base Mundial de Datos de Felicidad de Ruut Veenhoven. En tercer lugar está el sitio de la enciclopedia Wikipedia que esboza el enfoque de Felicidad Auténtica de la psicología positiva de Martin Seligman (véase también Seligman, 2003). La psicología positiva se ocupa no solamente de la 'felicidad' experimentada, como en la prueba de Diener, sino también de actividades y sentimientos — con compromiso, absorción, curiosidad y "flujo". Consecuentemente, el sitio en línea "Felicidad Auténtica" de Seligman ofrece una serie de pruebas — no sólo de felicidad, también de fortalezas de carácter. De veinticuatro fortalezas personales posibles, mis registros más elevados fueron en "coraje y valor", así como en "creatividad, ingenuidad y originalidad"; mis registros más bajos aparecieron en "espiritualidad, sentido de propósito y fe" y en "modestia y humildad”. Más aún, se pueden encontrar encuestas acerca de medidas para evaluar la felicidad como, por ejemplo, en Kahneman et al. (2004), "Método de la reconstrucción del día”.

La agenda de la felicidad no está, sin embargo, totalmente monopolizada por gurús de la autoayuda, sino que se ha convertido en componente integrante de la agenda política. Durante veinte años el Centro de Pronóstico Henley ha estado preguntando al público británico: “Usted piensa $[\ldots]$ que la calidad de vida [...] mejora más por: a) preocuparse por los intereses de la comunidad antes que por los propios, $\mathrm{o} b$ ) velar primero por uno mismo, lo que al final aumenta los estándares para todos?" (Aitkenhead, 2006). Este tipo de conjetura y antítesis infundadas es común en la retórica de la política neoliberal y en sondeos de opinión (Levitas, 1998; Fairclough, 2000).

En consecuencia, cuando un político de derecha expresa que: "Debemos pensar no sólo en lo que es bueno para llenar de dinero los bolsillos de la gente, sino también en 
qué es bueno para llenar de alegría sus corazones 6", esto me infunde miedo: el "no sólo" significa una degradación de los conceptos de distribución equitativa y pobreza relativa, favoreciendo en cambio la exhortación a realizar cambios en el estilo de vida. El problema con los valores posmaterialistas es que distraen la atención de las carencias materiales absolutas y relativas que caracterizan la vida no sólo de los países más pobres, sino de muchas de las sociedades opulentas también.

Una recapitulación más seria del estado que guarda la investigación acerca de la satisfacción en la vida sugiere que lo económico sigue siendo fundamental. México presenta aproximadamente los mismos niveles de satisfacción que Gran Bretaña y alrededor de un tercio de su Producto Interno Bruto (PIB) per capita en 1995 (Donovan y Halpern, 2002: 10). De hecho, en 1981 los registros de satisfacción en la vida en México fueron superiores a los de Estados Unidos y el Reino Unido, aunque decayeron abruptamente en la década de 1980 y se recuperaron parcialmente en la década de 1990. El informe sugiere que tales fluctuaciones en los registros de países individuales son principalmente el resultado de cambios sociales, mientras que muchas de las diferencias al comparar entre países pueden ser de origen cultural: "se piensa que los mayores niveles de satisfacción que registran los países latinoamericanos, a pesar de bajos PIB per capita, reflejan parcialmente una disposición cultural hacia la vida" (Donovan y Halpern, 2002: 18). Pero ésta es la excepción: en conjunto, la satisfacción en la vida es mayor en los países ricos que en los pobres. Inclusive, cuando se desciende del nivel agregado al individual, se confirma que dentro de un país, en lo individual, la gente más rica es más feliz que la pobre y que los aumentos del ingreso personal conducen a aumentos en la satisfacción declarada en la vida (Donovan y Halpern, 2002: 16). Inversamente, como es bien sabido, la gente más pobre padece elevados niveles de angustia y depresión. Estas asociaciones transversales prevalecen. Pero las series cronológicas muestran un patrón diferente: los incrementos en la riqueza agre-

\footnotetext{
${ }^{6}$ David Cameron, líder del Partido Conservador Británico, 2006, en $<$ http://newsvote.bbc.co.uk/1/hi/ptogrammes/happiness_formula/ 4809828.stm>, consultado el 3-VII-2006.
}

gada a lo largo del tiempo no son acompañados del correspondiente (o algún) incremento promedio en la felicidad, tanto porque la gente se acostumbra a mayores niveles de consumo como porque el dinero no es el único factor que influye en la felicidad. Donovan y Halpern listan una serie de factores relacionados con la satisfacción en la vida. En lo individual incluyen: predisposición genética; optimismo, extroversión y autoestima; género (las mujeres expresan mayor grado de satisfacción que los hombres); edad; ingreso; satisfacción en el trabajo; desempleo; salud; ociosidad, incluyendo ejercicio y labores de jardinería; participación en la religión; y relaciones. Los autores alertan que, pese a que las investigaciones muestran con claridad que los que están casados son mucho más felices que los solteros, divorciados o viudos, no sabemos si esto se debe a que los que ya son de alguna manera felices tienen más probabilidades de casarse y permanecer casados. Resulta interesante que la educación tiene poco efecto sobre la satisfacción en la vida, al margen de su impacto en el mercado de trabajo. A nivel agregado, la satisfacción en la vida parece estar afectada por niveles de desempleo, desigualdad, gobernanza y democracia.

\section{EL PROBLEMA DEL CRECIMIENTO ECONÓMICO}

Las mediciones de la satisfacción en la vida constituyen un enfoque simplista e inadecuado al tema del florecimiento humano y su banalidad hace que se presten al abuso político. Pero existen añejas críticas al crecimiento económico como indicador del bienestar social, al mismo tiempo que intentos más nuevos y sofisticados por descubrir indicadores directos del bienestar. Las objeciones a las virtudes del crecimiento económico per se se remontan al menos al siglo XIX y al rápido 'desarrollo' de la primera nación industrial, Gran Bretaña.

Comentaristas como John Ruskin, desde la perspectiva moral y estética del romanticismo, objetaron que mucho de lo que era producido con vista a la ganancia, más que al uso, constituía perjuicio más que riqueza. Marx, por supuesto, simultáneamente exaltó las capacidades pro- 


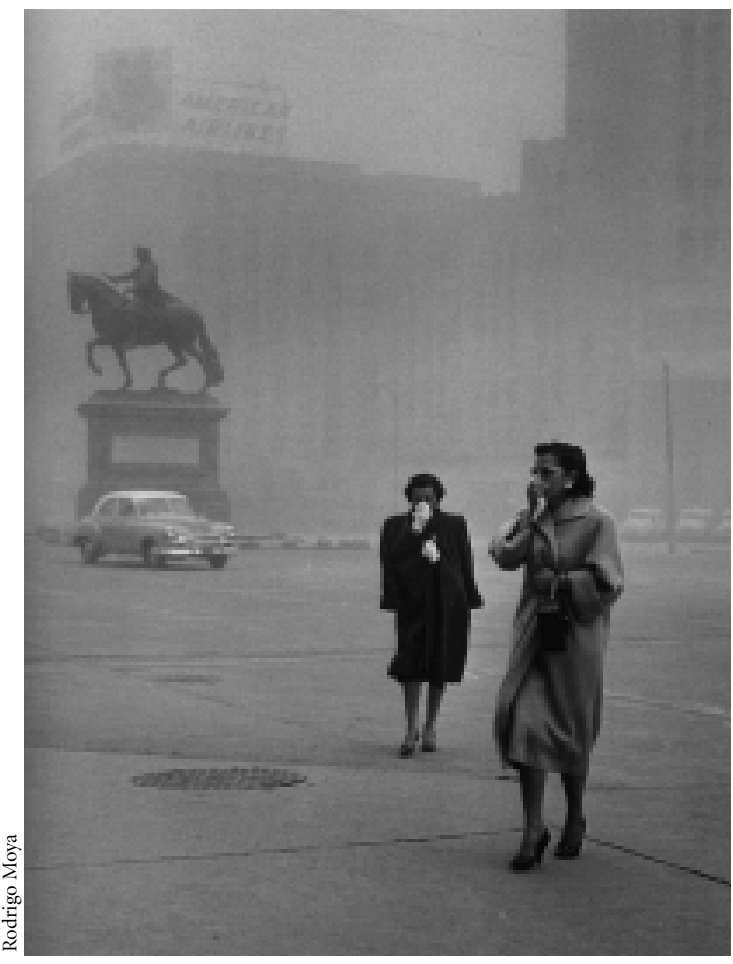

Avenida Juárez, ciudad de México, ca. 1963.

ductivas del sistema industrial y desarrolló un análisis de la explotación económica y el daño humano resultantes. William Morris combinó ambas cosas en una síntesis utópica marxista que se despliega a lo largo de sus escritos políticos (véase Morris, 2005) así como en su novela utópica News from Nowhere (Noticias de ninguna parte) (Morris, 1891). Un siglo después, la misma crítica despiadada a las consecuencias humanas del capitalismo y la posibilidad de una alternativa tiñeron la obra de Ivan Illich, fundador del Centro Intercultural de Documentación (CIDOC) en Cuernavaca, México. La cuestión del transporte fue central en las objeciones económicas y ecológicas de Illich al capitalismo: la bicicleta es, argüía, no sólo ecológicamente preferible al automóvil sino también más eficiente energéticamente (Illich, 1973). La producción y el consumo de petróleo se encuentran actualmente en el centro de la política global.

Las objeciones detalladas al PIB como medida del crecimiento económico han surgido predominantemen- te de feministas y ecologistas. Waring (1988) argumenta que debido a que típicamente el PIB excluye todo el trabajo que se hace fuera del mercado ignora una gran cantidad de trabajo socialmente necesario que es realizado, en esas circunstancias, generalmente por mujeres. Incluso en el Reino Unido, aproximadamente la mitad de toda la actividad económica ocurre fuera del mercado (Levitas, 1998: 8; Donovan y Halpern, 2002: 46). Algunos incrementos del PIB pueden resultar del simple hecho de incorporar al mercado actividades que se hacían fuera de él. Además, todas las actividades del mercado, sean o no socialmente útiles, son consideradas en el PIB —incluyendo los costos de limpieza de desastres ecológicos como los derrames de aceite, así como los de control de la criminalidad. Aun actividades abiertamente nocivas, como las industrias del tabaco y el alcohol, cuentan como logros inequívocos desde la óptica del PIB. Dada la debilidad del PIB como instrumento de medición, no sorprende que su correlación con los niveles de satisfacción en la vida sea imperfecta. Más interesantes son los intentos por encontrar mediciones alternativas como el Índice de Bienestar Económico Sostenible (IBES) y la Medición del Progreso Doméstico (MPD). El IBES deduce los costos ambientales y sociales y adiciona el valor del trabajo doméstico. El MPD, más reciente, incluye los costos de la criminalidad y la ruptura familiar, y utiliza un método diferente para contabilizar los cambios climáticos y el agotamiento de los recursos naturales. Tanto el IBES como el MPD hacen deducciones por la desigualdad como mal social o costo, porque reduce la satisfacción en la vida (NEF, 2004). La medida en que la desigualdad reduce la satisfacción, como apuntan Donovan y Halpern (2002), es variable tanto al interior de una sociedad como entre sociedades. La desigualdad, por supuesto, tiene impacto sobre el bienestar objetivo, en tanto reduce la esperanza de vida (Wilkinson, 2005). Mientras que el PIB ha crecido constantemente en el Reino Unido desde 1950, el IBES creció lentamente hasta la mitad de la década de 1970, y luego declinó hasta su nivel de 1950 hacia la mitad de la de 1990 (Donovan y Halpern, 2002). El MPD creció lentamente hasta la mitad de los años setenta; luego comenzó a descender ligeramente, regresando al final de la de 1990 al nivel que alcanzó en 1976, y después 
permaneció estático (NEF, 2004). Puede ser significativo que el punto más elevado del MPD en Gran Bretaña coincida con los registros más bajos de pobreza y desigualdad. Hay una relación mucho más estrecha de los cambios en el MPD a lo largo del tiempo y el cambio (o la ausencia de éste) en la satisfacción subjetiva en la vida, por lo menos en Gran Bretaña, que la que se observa entre el PIB y dicha satisfacción; en cambio, la brecha entre el PIB y el MPD es indicativa de un crecimiento que no es sostenible ecológica ni socialmente. Índices semejantes han sido desarrollados en otros trabajos: el Indicador de Progreso Auténtico (IPA) de Estados Unidos muestra una declinación global en la segunda mitad del siglo XX, comparada con un enorme crecimiento en el PIB. El IPA australiano muestra una divergencia mucho menor con el PIB, pero permanece por debajo de la curva de éste (Donovan y Halpern, 2002).

Medidas como el IBES, el MPD y el IPA siguen siendo indicadores de bienestar económico: en ellas, los costos sociales son incluidos como costos económicos. Junto a lo anterior, las mediciones de Calidad de Vida han devenido en una pequeña industria académica. Existe una Sociedad Internacional de Estudios de la Calidad de Vida (ISQOLS por sus siglas en inglés), con base en Estados Unidos, cuya séptima conferencia anual se realizará en $2006^{7}$. Un Índice de Salud Social, aplicado en Canadá y Estados Unidos, muestra de igual manera divergencias con el PIB —que inician en 1970 para Estados Unidos y en 1980 para Canadá. El Índice de Desarrollo Humano de Naciones Unidas, recopilado para 177 países, incorpora PIB, esperanza de vida y educación. El informe de 2005, como los anteriores, agrupa las naciones en niveles de desarrollo humano alto, medio y bajo. Noruega figura en primer lugar, Estados Unidos en décimo, Reino Unido en el decimoquinto y México en el cincuenta y tres - todos en el grupo de desarrollo 'alto'. Al final está Níger (Programa de Naciones Unidas para el Desarrollo, 2005: 220), junto con varias otras naciones africanas. Este informe también identifica desigualdades al interior de un país y entre países, como una importante barrera para alcanzar las Metas de Desarrollo del Milenio. El Índice Ponde-

\footnotetext{
$7<$ www.isquols.org $>$.
}

rado de Progreso Social (WISP, por sus siglas en inglés), integrado por 46 indicadores sociales separados, coloca en 1995 a Noruega en segundo lugar, al Reino Unido en el lugar diez y siete, Estados Unidos en el veintisiete y México en el sesenta y cinco (Estes, 1995; Donovan y Halpern, 2002). La posición 'objetiva' de México en los cuadros de desarrollo/calidad de vida es muy inferior a la que se obtiene en las mediciones de satisfacción en la vida.

Tales mediciones del progreso económico y la calidad de vida generalmente son construidas a nivel agregado - y en la mayoría de los casos el nivel agregado es nacional. Lo atractivo de la 'felicidad' es que puede ser aplicada a individuos reales. La idea aún más amplia de bienestar, que puede contener tanto elementos objetivos como subjetivos, puede tener una conexión más cercana con el florecimiento humano. La pobreza debería regresar entonces a la agenda. Virtualmente toda investigación sobre pobreza y desarrollo refleja que la pobreza tiene efectos adversos sobre el bienestar; es esto, ante todo, lo que la convierte en una preocupación moral apremiante. Tanto la pobreza absoluta como la total $^{8}$ afectan la salud física y mental, el desarrollo educacional y la participación social y cívica.

La New Economics Foundation (NEF), que ha sido pionera en mediciones como el IBES y el MPD, ha intentado también diseñar indicadores subjetivos del bienestar a nivel individual, que van más allá de la felicidad declarada o la satisfacción en la vida, e hicieron una prueba piloto con niños y jóvenes en una ciudad en particular (Marks, Shah y Westall, 2004). Estos indicadores de nivel individual incluyen las mediciones de la satisfacción en la vida, pero van más allá de éstas. Utilizan el enfoque de la psicología positiva que concibe que el involucramiento activo y el uso de habilidades contribuyen a la felicidad. El modelo es multidimensional y está ubicado conceptualmente en el triángulo de bienestar económico, ambiental y social. A nivel individual, el bienestar se caracteriza por dos dimensiones: satisfacción en la vida, que puede ser considerada a través de los diversos ámbitos de la familia, la amistad, el vecindario y la escuela; y el desarrollo per-

\footnotetext{
${ }^{8} \mathrm{La}$ autora se refiere a las definiciones de pobreza adoptadas en la Reunión Cumbre sobre Desarrollo Social de la ONU, realizada en 1995. [Nota del coordinador del número, Julio Boltvinik.]
} 
sonal, la curiosidad y el involucramiento. El estudio contempla también la conducta pro-social y la cooperación, así como la autoestima. Este estudio, relativamente breve, no es común, pues capta información sobre los niños directamente de ellos mismos. Se confirma con esto que involucramiento y satisfacción son dimensiones separadas. La conducta pro-social, si bien más estrechamente ligada con el involucramiento, no estaba muy relacionada con ninguna de las dos dimensiones del bienestar. La pobreza, medida a través de la variable proxy de 'ningún adulto empleado en el hogar', se asoció con menores puntajes en ambas dimensiones del bienestar. Los niños de mayor edad mostraron niveles drásticamente menores de bienestar que los niños más pequeños. Niños menores de 12 años con el más elevado desempeño escolar tuvieron niveles significativamente inferiores de bienestar que los otros - lo que sugiere que éxito en la educación y bienestar son, en algunos casos, antitéticos. Puesto que la curiosidad se utilizó como variable proxy del involucramiento, esto resulta consistente con la bibliografía más radical sobre educación. Deschooling Society de

Illich (1972), así como How Children Learn (1991 [1970]) y How Children Fail (1990 [1964]) de John Holt, enfatizan la relación entre éxito escolar, conformidad y deseo de aprobación.

\section{IMAGINAR EL FLORECIMIENTO HUMANO}

A raíz de este estudio, la New Economics Foundation produjo A Well-being Manifiesto for a Flourishing Society (Shah y Marks, 2004). Éste declara que: "Uno de los objetivos clave de un gobierno democrático es promover la buena vida: una sociedad floreciente en la que los ciudadanos son felices, sanos, competentes e involucrados - en otras palabras, con altos niveles de bienestar" (Shah y Marks, 2004). Y: "Nosotros hemos alcanzado un elevado nivel de vida. Pero debemos cuidar que un enfoque concentrado en la eficiencia económica no destruya las causas reales del bienestar en nuestra sociedad" (Shah y Marks, 2004: 2). El manifiesto plantea ocho áreas en las cuales se requieren cambios y en las que el gobierno podría, en su opinión, actuar:
- Medir lo importante.

- Crear una economía de bienestar (well-being).

- Recuperar nuestro tiempo.

- Crear un sistema educativo que promueva el florecimiento.

- Reorientar el sistema de salud para promover la salud integral.

- Invertir en la primera infancia y en la paternidad.

- Desalentar el materialismo y promover la publicidad genuina.

- Fortalecer la sociedad civil, el bienestar social y la ciudadanía activa.

En algunos sentidos, la imagen descrita por este manifiesto es utópica en el mejor sentido de la expresión, esto es, conjura la imagen de una sociedad muy diferente y mejor. Trabajo de alta calidad, un máximo de 35 horas de trabajo a la semana, protección del ambiente, un sistema educativo cuyo propósito es "crear personas jóvenes capaces y emocionalmente bien desarrolladas, felices y motivadas". Revalorar ampliamente la paternidad. No permitir publicidad comercial dirigida a los niños. Disipar "la ilusión de que los bienes materiales traerán felicidad" y "abandonar nuestros pasatiempos nacionales de ir de compras y ver televisión" mediante la provisión de más parques, centros deportivos y centros de arte a nivel local (Shah y Marks, 2004: 3). Un ingreso ciudadano pagadero a todas las personas, inclusive a los niños, "independientemente del estatus de sus empleos o circunstancias sociales" (Shah y Marks, 2004: 10).

Desde otros ángulos, el proyecto es utópico en el sentido despectivo de que no es realista. Primero, la visión implícita de la sociedad existente es muy desorientadora al omitir mención alguna a los niveles actuales de desigualdad. La afirmación "hemos alcanzado un elevado nivel de vida" mezcla indicadores agregados con circunstancias individuales, ignorando los persistentes y altos niveles de pobreza —no solamente bajos ingresos, sino también privación material y social directamente medida en todos los grupos de edad. Segundo, aunque la sociedad prevista en el manifiesto puede no ser intrínsecamente inalcanzable, es inconsistente con las fuerzas motrices del capitalismo global neoliberal. Se ignoran los temas de la propie- 
dad de los medios de producción, de la tierra y los inmuebles. También se ignora la presión a la baja de los niveles salariales, originada por los movimientos del capital y de los puestos de trabajo. Los tipos de empleo generados en una economía flexible y la tensión entre éstos y el "trabajo de alta calidad" no son reconocidos a pesar de la recomendación de que "los empleos deben rediseñarse para que se ajusten a las fortalezas e intereses particulares de la gente" y la sugerencia de que debe dotarse a los trabajadores de mayor autonomía (Shah y Marks, 2004). La justicia social es ignorada en gran medida. Y de hecho, se presta poca atención a qué actividades se debieran continuar realizando, cuáles cambiar y cuáles suspender en beneficio de la sustentabilidad ambiental, y cómo los cambios necesarios se impondrían en un contexto neoliberal. Una genuina visión utópica establecería condiciones estructurales para que tales cambios ocurrieran.

La visión es también algo menos que utópica. Esto se debe en parte a que pretende conceptualizar una sociedad floreciente al mismo tiempo que proveer cursos de acción inmediatos hacia ella, lo cual aleja el proyecto de la visión utópica y lo acerca a las políticas. He argumentado en otro lugar que éste es un error grave en el pensamiento sobre política social (Levitas, 2001)9. Pero hay un problema más fundamental. La conceptualización del bienestar y de sus consecuencias positivas se ve limitada por lo que se entiende como bienestar en el capitalismo. La atractiva formulación de "gente joven capaz y emocionalmente bien desarrollada, que vive feliz y motivada" conlleva peticiones de principio. ¿Capaz de quée, ¿ motivada a hacer qué?, ¿feliz en qué sentido? Y ¿qué debe entenderse por "emocionalmente desarrollada"? Una respuesta parcial y no muy utópica es proporcionada por la afirmación de que "un sistema de educación que promueve el florecimiento conducirá a mayor productividad, a una sociedad más empresarial y a una ciudadanía más activa" (Shah y Marks, 2004: 3). De la misma manera se puede argumentar lo contrario: el florecimiento conducirá a menor productividad, pues habrá un reconocimiento amplio de la observación de Shakespeare de

${ }^{9}$ Para una discusión más amplia de la idea de utopía y su centralidad en la transformación social, véase Levitas, 1990 y 2006. que "en obtener y gastar desperdiciamos nuestras horas". Esto será magnífico para el medio ambiente, pero solamente será excelente para la justicia social y el aumento del bienestar si la menor productividad es distribuida más uniformemente. Como lo dijo Marcuse, "muchos tendrían que renunciar a las comodidades manipuladas para que todos pudieran vivir una vida humana" (Marcuse, 1955: 137). El florecimiento también conduciría, con suerte, a una sociedad menos empresarial, puesto que los empresarios son aquellos que buscan ganar dinero a partir de sus capacidades y capabilities.

El problema de la capability y la motivación es aquí, precisamente, el mismo de la capability en el trabajo de Amartya Sen, cuyo Development as Freedom (2001) ha atraído a una audiencia muy amplia. Sen señala que el desarrollo debe ser entendido en términos del desarrollo de las capabilities humanas (Sen, 2001; véase también Sen, 1995). Como los críticos han apuntado, lo que realmente sucede en la exposición de Sen es que las capabilities a desarrollar son siempre aquellas que se valoran en el mercado (Townsend, citado en Boltvinik, 2005, y Levitas, 2004). La noción de un ser humano capaz se ve acotada en el contexto de la economía neoliberal a un actor económico capaz. Las capabilities, como las concibe Sen, son en esencia económicas y muy distantes de como concibe Marx las capacidades, cuya Crítica del Programa de Gotha (1968[1875]) es una clara advertencia del error de constreñir las mediciones de las capacidades humanas a una escala única.

Shah y Marks sostienen su Manifiesto por medio de referencias a teorías de la necesidad derivadas en parte de Abraham Maslow (1943) y en parte del economista chileno Manfred Max Neef (1991). La jerarquía de las necesidades de Maslow inicia con las necesidades fisiológicas, continúa con las de seguridad, las necesidades sociales y las de estatus y estima. Una vez que las necesidades básicas son satisfechas, las necesidades de reconocimiento y autorrealización entran en juego. El énfasis en la autorrealización corresponde con la dimensión de involucramiento del bienestar. El enfoque de Max Neef no establece jerarquías; genera una matriz combinando los ejes de las necesidades existenciales y axiológicas, que pueden ser satisfechas con satisfactores socialmente disponibles. 


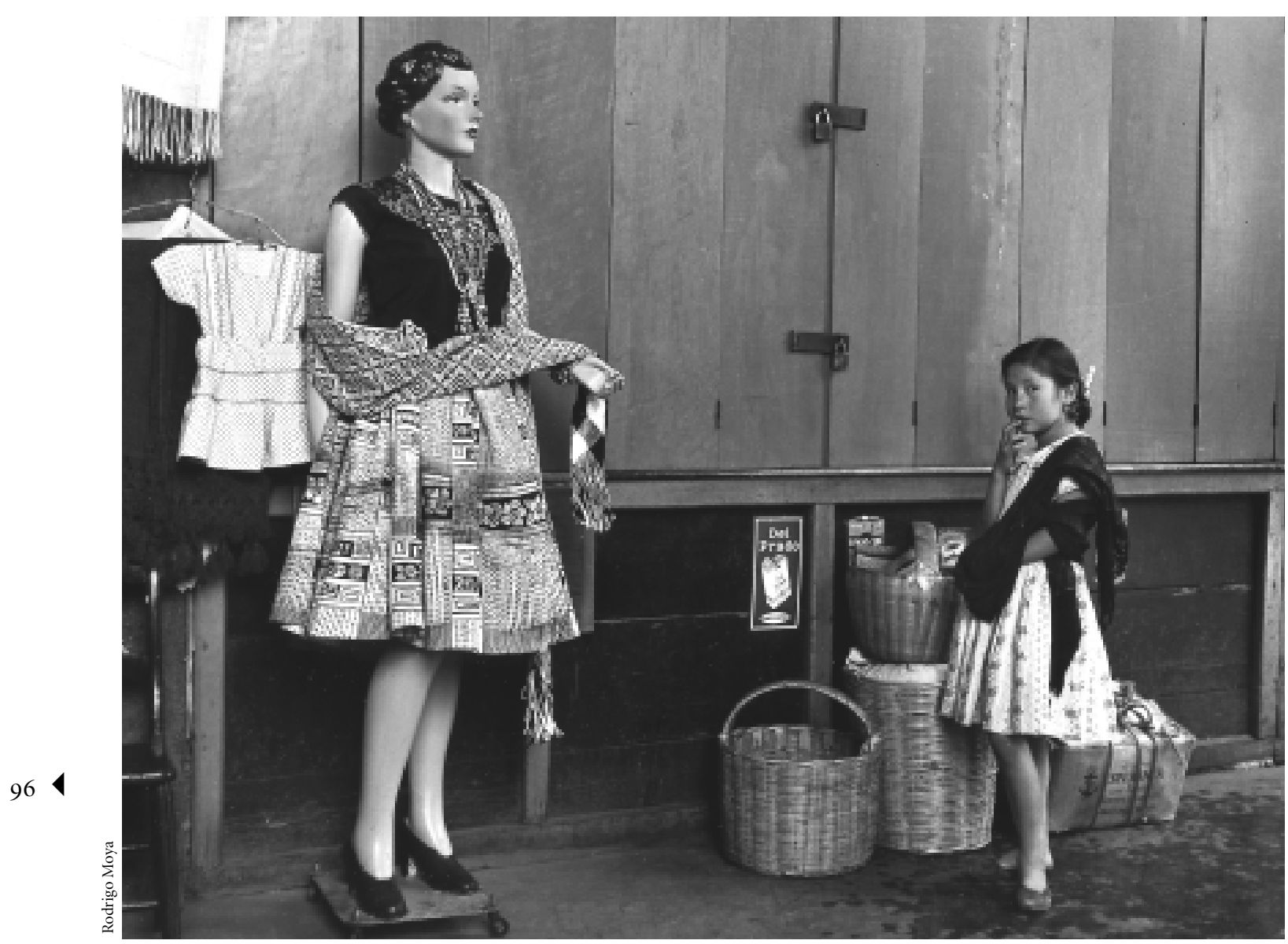

Mercado de Oaxaca, 1963.

Los satisfactores no corresponden de manera exacta con las necesidades: los mejores, los sinérgicos, satisfacen varias necesidades simultáneamente, en tanto que los satisfactores inhibitorios satisfacen necesidades particulares pero impactan negativamente sobre la satisfacción de otras, y los pseudo-satisfactores proporcionan una falsa sensación de satisfacción. Si bien Max Neef no acepta la distinción entre necesidades "básicas" y "superiores" propuesta por Maslow, sí reconoce una diferencia entre necesidades y apetencias (wants). Aunque declaran preferir a Max Neef que a Maslow, precisamente porque las necesidades se tratan como un sistema integrado, Shah y Marks recurren insistentemente a la idea de "necesidades básicas", sosteniendo que la ganancia material tiene poco impacto sobre el bienestar una vez que dichas necesidades están satisfechas. Se supone entonces que la sociedad buena es aquella en la cual las necesidades no exceden a las satisfacciones disponibles ${ }^{10}$.

El problema esencial es que las necesidades, las apetencias y las satisfacciones, y las incompatibilidades en-

\footnotetext{
${ }^{10}$ El recuento de la concepción de las necesidades de Maslow por parte de Shah y Marks, y que Ruth Levitas relata sin modificar, es inexacto. La distinción de Maslow es entre necesidades bajas (no básicas) y necesidades superiores. Concibe todas las necesidades incluidas en su teoría de la jerarquía como básicas, incluyendo la autorrealización. Sólo las necesidades cognitivas y estéticas, que Maslow presenta fuera de la jerarquía de necesidades, no son calificadas como básicas. Por otra parte, Maslow no habla de necesidades sociales. [Nota del coordinador del número, Julio Boltvinik.]
} 
tre ellas, son generadas socialmente. Como ha señalado William Leiss (1978), el capitalismo es un sistema en el que existen límites intrínsecos a la satisfacción. Éste opera precisamente mediante la generación constante de nuevas necesidades y apetencias, y la introducción de nuevos satisfactores al mercado, generando una creciente carga al tener que elegir, así como una creciente brecha de escasez. De manera importante, en una crítica a Marcuse, Leiss pone en duda la posibilidad de distinguir entre necesidades y apetencias, o entre necesidades 'reales' y 'falsas'. Esto es porque (como también lo acepta Max Neef) mientras la distinción entre necesidades básicas y superiores puede ser defendible a cierto nivel de abstracción, en la práctica las necesidades y los satisfactores funcionan como una formación histórica concreta, en la cual los medios para enfrentar las necesidades tienen en sí mismos un significado social. La distinción entre necesidades básicas y superiores se desvanece entonces en la práctica. Este también es el mensaje central de Fred Hirsch en Social Limits to Growth (1995[1979]): lo que hace deseables a muchos bienes y actividades descansa precisamente en el hecho de que están disponibles sólo para unos cuantos y confieren estatus, de manera que los bienes situacionales sólo "funcionan sobre bases temporales". Éstos pueden parecer viejos argumentos. Sin embargo, Marcuse, Leiss y Hirsch - y otros como Erich Fromm- escribían cuando el control hegemónico del capitalismo era más débil, antes de la invención de la frase "no hay alternativa”. Todavía era posible visualizar una sociedad transformada, en la que el florecimiento humano se podía imaginar a partir de una articulación social distinta de las necesidades. El proyecto utópico, la imaginación de una sociedad alternativa involucra, como argumentó Miguel Abensour, no la eliminación de las necesidades, sino su transformación:

En una aventura así ocurren dos cosas: nuestros valores habituales (el sentido común de la sociedad burguesa) son arrojados al caos. Y entramos a la utopía propiamente y a un espacio nuevo: la educación del deseo. Esto no es lo mismo que una educación moral dirigida a un propósito determinado: es, más bien, abrir un camino a las aspiraciones, "enseñar al deseo a desear, a desear mejor, enseñar a desear más y sobre todo a desear de manera diferente (Thompson, 1976: 790-791).
La bibliografía sobre políticas para promover la felicidad y el bienestar (ni qué decir sobre pobreza, desarrollo y capabilities), casi no entra a este registro utópico. Cae, en cambio, en la obviedad de que el dinero no puede comprar la felicidad. Ciertamente así es, pero el dinero hace más que permitir al rico ser miserable dentro de su comodidad. Los pobres en una sociedad opulenta mueren más jóvenes, son menos sanos, sufren mayor angustia mental, carecen de oportunidades de educación formal, tienen menos probabilidades de aprender a tocar un instrumento musical, a nadar, a esquiar, de viajar ampliamente, y llevan vidas laborales menos satisfactorias. También son sometidos a la falta de reconocimiento y la humillación, que son el meollo de las relaciones de clase (Sayer, 2005). La mejor respuesta la da el poeta socialista Bruce Glasier (1891: 54), nacido en 1859:

Vivir sencillamente puede conducir a la salud, y virtudes maravillosas pueden abundar debajo de costillas de carnes magras y bolsillos escasos de paga.

Quizá la pobreza sea mejor

si se comprende correctamente:

pero volteará las cosas al revés, jóvenes, no deseamos todo el bien ${ }^{11}$.

El problema, sin embargo, no es simplemente que el carácter antiutópico del discurso público retraiga las discusiones de felicidad y bienestar a un marco capitalista, pese a que intente trascenderlo, sino que la idea misma de florecimiento humano es una idea utópica, que estira los grilletes de la imaginación, pero que está necesariamente encadenada a ellos. Hay límites a lo que podemos imaginar como posible, y una de las funciones de la imaginación utópica consiste en mantenernos atentos. En este sentido, el intento de imaginar la utopía, la sociedad en

\footnotetext{
${ }^{11}$ Plain living may be wholesome,

And wondrous virtues may

Abound beneath ribs scant of flesh

And pockets scant of pay.

It may be poverty is best

If rightly understood:

But will turn things upside down, my lads!

We don't want all the good.
} 
la que el florecimiento humano se torna posible, es necesariamente un fracaso. El proyecto de movilizar un concepto utópico dentro de los confines de una sociedad lejana de la utopía y marcada por la pobreza y la desigualdad siempre enfrenta este problema.

Esta dificultad puede encontrarse también en el enfoque de Julio Boltvinik ${ }^{12}$. La crítica de Boltvinik a los estudios de pobreza existentes consiste en que casi invariablemente reducen la pobreza y la riqueza humanas al eje económico. Esto, dice él, es cierto aun en el caso del intento de Townsend por definir una línea de pobreza objetiva, a pesar de la visión mucho más amplia de pobreza de la que parte este autor. El argumento de Boltvinik está exagerado aquí. Townsend argumenta que:

Se puede decir que los individuos, las familias y los grupos están en la pobreza cuando carecen de los recursos para obtener los tipos de dieta, participar en las actividades y tener las condiciones de vida y las instalaciones que se acostumbran, o por lo menos que son ampliamente promovidas o aceptadas, en las sociedades a las que pertenecen. Sus recursos están tan seriamente por debajo de los que dispone el individuo o la familia promedio que resultan, en efecto, excluidos de los patrones ordinarios de vida, costumbres y actividades (Townsend 1979: 32).

Él sí argumentó, sin embargo, que era posible definir empíricamente un nivel de ingreso por debajo del cual esta exclusión era inevitable. Empero, la tendencia a regresar al eje económico se halla presente indudablemente, por ejemplo, en la definición de la Organización de las Naciones Unidas de pobreza total:

La falta de ingresos y recursos productivos para asegurar una subsistencia sostenible; hambre y desnutrición; mala salud; acceso limitado o nulo a los servicios; mayores índices de morbilidad; falta de vivienda o vivienda inadecuada; medio ambiente inseguro, y discriminación social y exclusión. También se caracteriza por la falta de participación en la toma de decisiones y en la vida civil, social y cultural (ONU, 1995).

12 Espero hacer justicia razonable aquí a la amplia obra del profesor Boltvinik. La he oído expuesta y discutida en inglés, y estoy muy agradecida con el profesor Boltvinik por haberme proporcionado un resumen en inglés. Pero no he podido leer la obra completa pues mi español es inadecuado (Boltvinik, 2005).
No obstante, aunque cuestiones sociales han sido incorporadas a la agenda de pobreza, en gran medida a través del concepto de exclusión social, prevalece el hecho de que la pobreza se asocia generalmente con la carencia de recursos materiales. Los estudios empíricos de exclusión social han mostrado también que las carencias materiales son una de sus causas importantes (Pantazis, Gordon y Levitas 2006).

Coincidiendo con los partidarios del bienestar, Boltvinik señala que el objeto de la política social debería ser la promoción del florecimiento humano, y que la realización de las potencialidades humanas no debe confundirse con la abundancia material. Para que así ocurra, el florecimiento humano debe ser incorporado explícitamente en nuestra comprensión de la pobreza. Aquí el florecimiento humano es mucho más que satisfacción en la vida o aun que el ejercicio de habilidades: es el desarrollo del potencial humano - involucrando el desarrollo tanto de capacidades como de necesidades. La argumentación aquí es radicalmente distinta a la de la mayoría de los debates de las necesidades humanas fuera del contexto marxista, pues su fundamento radica en que las capacidades y las necesidades se expanden con el florecimiento humano. Mientras más desarrolladas tenga sus capacidades una persona, mayores serán sus necesidades. Decir que sus necesidades son mayores no implica, necesariamente, que sus necesidades de consumo tengan que ser mayores, una vez que las necesidades básicas están resueltas. Esto, considero, requiere un mayor análisis. Boltvinik pone como ejemplo de profundización de necesidades que el oído educado necesita buena música. Pero esto requiere de la disponibilidad de buena música, que a su vez requiere músicos, instrumentos y maestros. Se incurrirá en uso de recursos (costo) para otorgar a todos el instrumento musical de su elección, pese a que será menor al uso de recursos y a la contaminación que significaría proveer a todos de un automóvil.

De aquí resulta evidente que Boltvinik acepta la problemática distinción que hace Maslow entre necesidades bajas y superiores, así como la distinción entre necesidades y apetencias. Argumenta que la diferencia es demostrable por el daño humano que se ocasiona cuando las necesidades, en oposición a los deseos, no son satisfechas. 
Sin embargo, si el daño se entiende como obstáculo al florecimiento humano, la distinción deviene otra vez problemática. Empero, el hecho de que las necesidades básicas no estén satisfechas para la mayoría de la población en el mundo necesariamente inhibe el florecimiento humano: superar la pobreza económica es condición necesaria pero de ninguna manera suficiente para el florecimiento humano. Los obstáculos al florecimiento están no solamente en los recursos económicos, sino también en la posibilidad de ejercitar (y desarrollar) capacidades y habilidades. La naturaleza del trabajo de mucha gente bajo la alienación capitalista no es autorrealizadora, pues involucra solamente un rango estrecho de capacidades, obstaculizando así su desarrollo y la expansión de necesidades. De manera consecuente, Boltvinik distingue un "eje del florecimiento humano" de un "eje del nivel de vida” confinado a riqueza/pobreza económica. Señala, no obstante, que el eje del nivel de vida debe ser entendido como una abstracción del eje del florecimiento humano, que es lógica y conceptualmente más importante, así como mucho más amplio.

Boltvinik hace una clara diferenciación de los ámbitos de lo individual y lo societal. La pobreza y la riqueza humanas (como el bienestar) se ubican en el individuo, pero dependen de la presencia o ausencia de las condiciones sociales para el florecimiento humano (que incluye pero no se limita a las condiciones económicas). Esta diferencia está presente implícitamente, aunque con frecuencia con debilidad, en la bibliografía sobre política de bienestar. Boltvinik hace además una distinción entre el ser y el estar (lo estructural y lo circunstancial) de la condición humana tanto a nivel humano como económico. La riqueza/pobreza humana está estructuralmente caracterizada por altos/bajos niveles de necesidades y altos/bajos niveles de desarrollo de capacidades. Circunstancialmente, está caracterizada por la satisfacción de necesidades efectivas y la aplicación de capacidades efectivas. En el nivel económico, la cuestión estructural consiste en si los recursos y las condiciones están disponibles para el desarrollo de necesidades y capacidades; el nivel circunstancial concierne a los recursos y condiciones para la satisfacción de necesidades efectivas y la aplicación de capacidades efectivas. Esta separación de niveles es útil para exponer las limitaciones del discurso público general acerca del bienestar y la felicidad, que actúa completamente en el nivel circunstancial tanto para el eje humano como para el económico.

Las cuestiones estructurales son también el espacio de una implícita crítica utópica: ¿cuáles necesidades y capacidades son convocadas en las condiciones reales existentes? ¿Qué gama de necesidades y capacidades podemos recomendar como constitutivas del florecimiento humano? ¿Cuáles pudieran ser las condiciones de este desarrollo? A este nivel, la distinción problemática entre necesidades básicas y superiores sería redundante: ésta es conceptualmente necesaria exclusivamente en la pobreza humana y económica del presente. La función de la utopía es actuar como crítica del presente, pero también sentar las bases para el diálogo sobre futuros deseables y las características humanas que serán producidas por ellos. Todas las discusiones de bienestar y florecimiento humano serían reforzadas haciendo más explícita la dimensión utópica. Esto enfocaría más finamente los límites de una agenda del bienestar que reprime las estructuras sociales y económicas que lo enmarcan. En el caso de Boltvinik esto aclararía el intento transformador de definir la pobreza y riqueza en términos de pobreza humana. Seguirá siendo válido que hay límites a lo que podemos imaginar como posible y que las necesidades y deseos en una sociedad mejor se desarrollarán más allá de los alcances de nuestra imaginación.

\section{Bibliografía}

Aitkenhead, Decca, 2006, "It's all about me", The Guardian, sábado 8 de julio, p. 23.

Boltvinik, Julio, 2005, Ampliar la mirada. Un nuevo enfoque de la pobreza y el florecimiento humano, tesis de doctorado, CIESAS-Occidente, Guadalajara.

Donovan, Nick y David Halpern, 2002, Life Satisfaction: the State of Knowledge and the Implications for Government, UK Government Strategy Unit.

Estes, Richard J., 1995, The World Social Situation, 1970-1995: Professional Challenges For a New Century, School of Social Work, Universidad de Pennsylvania, en $<$ http:/caster. ssw.upenn.edu/ restes/jak2.html>.

Fairclough, Norman, 2000, New Labour, New Language, Routledge, Londres. 
Glasier, Bruce, 1891, "We'll Turn Things Upside-Down”, en Bruce Glasier, On the Road to Liberty, National Labour Press, Londres.

Hirsch, Fred, 1995 [1979], The Social Limits to Growth, Routledge, Londres.

Holt, John, 1990 [1964], How Children Fail, Penguin, Harmondsworth.

— 1991 [1970], How Children Learn, Penguin, Harmondsworth.

Illich, Ivan,1972, Deschooling Society, Marion Boyars, Londres. — 1973, Energy and Equity, Marion Boyars, Londres.

Jameson, Fredric, 1981, The Political Unconscious: Narrative as a Socially Symbolic Act, Methuen, Londres.

_ 1984, The Seeds of Time, Columbia University Press, Nueva York.

_ 2004, Archaeologies of the Future: the Desire Called Utopia and other Science Fiction, Verso, Londres.

Kahneman, Daniel, Alan B. Krueger, David A. Schkade, Norbert Schwarz y Arthur A. Stone, 2004, "A Survey Method for Characterizing Daily Life Experience: The Day Reconstruction Method (DRM)", Science, vol. 306, 3 de diciembre, pp. 1776-1780.

Layard, Richard, 2005, Happiness: Lessons from a New Science, Allen Lane, Londres.

Leiss, William, 1978, The Limits to Satisfaction: An Essay on the Problems of Needs and Commodities, Marion Boyars, Londres.

Levitas, Ruth, 1990, The Concept of Utopia, Philip Allan, Londres.

_ 1998, The Inclusive Society?: Social Exclusion and New Labour, Macmillan, Basingstoke. ( $2^{\mathrm{a}}$ ed. en 2005.)

__, 2001, "Against Work: A Utopian Incursion into Social Policy”, Critical Social Policy, vol. 21, núm. 4, pp. 449-465.

__, 2004, "Beyond Bourgeois Right: Freedom, Equality and Utopia in Marx and Morris", The European Legacy, vol. 9, núm. 4, pp. 605-614.

— 2006, The Imaginary Reconstitution of Society: Inaugural Lecture at the University of Bristol, en <www.bristol.ac. uk/departments/sociology/staff/pubs/levitasinaugural $>$.

Marcuse, Herbert, 1955, Eros and Civilization, Vintage Books, Nueva York.

_-, 1968, One Dimensional Man, Sphere Books, Londres.

__, 1970a, Five Lectures, Allen Lane, Londres.

__, 1970b, An Essay on Liberation, Allen Lane, Londres.

Marks, Nic, Hetan Shah y Andrea Westall, 2004, The Power and Potential of Well-Being Indicators: Measuring Young People's Well-Being in Nottingham, New Economics Foundation, Londres.
Marx, Karl, 1968 [1875], Critique of the Gotha Programme, en Karl Marx y Friedrich Engels, Selected Works, Lawrence and Wishart, Moscú, Londres y Nueva York.

Maslow, Abraham H. (1943). "A Theory of Human Motivation”, Psychological Review, núm. 50, pp. 370-396.

Max Neef, Manfred A., 1991, Human Scale Development: Conception, Application and Further Reflections, Londres, Zed Books.

Morris, William, 1891, News from Nowhere, Longmans, Green \& Co., Londres.

—, 2005 , Escritos sobre arte, diseño y política, Doble, Sevilla.

NEF (New Economics Foundation), 2003, Making Indicators Count: Using Quality of Life Indicators in Local Governance, New Economics Foundation, University of the West of England, Londres.

— , 2004, Chasing Progress: Beyond Measuring Economic Growth, New Economics Foundation, Londres.

ONU, 1995, The Copenhagen Declaration and Programme of Action: World Summit for Social Development, 6-12 de marzo, United Nations Department of Publications.

Pantazis, Christina, David Gordon y Ruth Levitas (eds.), 2006, Poverty and Social Exclusion in Britain: The Millennium Survey, Policy Press, Bristol.

Programa de las Naciones Unidas para el Desarrollo (PNUD), 2005, Human Development Report 2005, United Nations Department of Publications.

Sayer, Andrew, 2005, The Moral Significance of Class, Cambridge University Press, Cambridge, Reino Unido.

Seligman, Martin, 2003, Authentic Happiness: Using the New Positive Psychology to Realise Your Potential for Lasting Fulfilment, Nicholas Brealey, Londres.

Sen, Amartya, 1995, Inequality Re-Examined, Oxford University Press, Oxford.

_ , 2001, Development as Freedom, Oxford University Press, Oxford.

Shah, Hetan y Nic Marks, 2004, A Well-Being Manifesto for a Flourishing Society, New Economics Foundation, Londres.

Thompson, Edward, 1976, William Morris: Romantic to Revolutionary, Merlin, Londres

Townsend, Peter, 1979, Poverty in the United Kingdom, Allen Lane and Penguin, Londres.

Waring, Marylin, 1988, If Women Counted, Macmillan, Londres.

Wilkinson, Richard, 2005, The Impact of Inequality: How to Make Sick Societies Healthier, Routledge, Londres. 